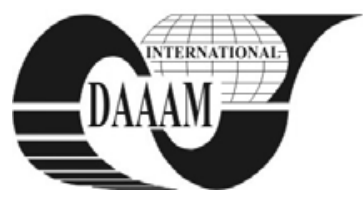

Annals of DAAAM for 2011 \& Proceedings of the 22nd International DAAAM Symposium, Volume 22, No. 1, ISSN 1726-9679 ISBN 978-3-901509-83-4, Editor B. Katalinic, Published by DAAAM International, Vienna, Austria, EU, 2011 Make Harmony between Technology and Nature, and Your Mind will Fly Free as a Bird Annals \& Proceedings of DAAAM International 2011

\title{
APPROXIMATION OF CO/LAMBDA BIOMASS COMBUSTION DEPENDENCE BY ARTIFICIAL INTELLIGENCE TECHNIQUES
}

\author{
PITEL, J[an] \& MIZAK, J[ozef]
}

\begin{abstract}
The paper describes some possibilities how to reach minimum $\mathrm{CO}$ in flue gases by control of biomass combustion process. One of the control system tasks is to find such amount of supplied oxygen described by parameter lambda, so that CO would be minimal. Considering a large scatter of the measured data the main point of paper is using of artificial intelligence techniques for approximation of the measured dependence $\mathrm{CO}=$ f(lambda). Two approximation tools have been tested: Neural Network Fitting Tool of Matlab and AForge.Neuro library based on Multilayer Feed Forward Neural Networks. The comparable results of approximation have been obtained by testing these tools on the real measured data.
\end{abstract}

Key words: approximation, artificial intelligence, biomass combustion

\section{INTRODUCTION}

Biomass and especially woodchips are fuels with very unstable composition in comparison with fossil fuels (coal, natural gas). The problem is to provide the combustion process of such fuel with acceptable economic and ecological conditions (combustion efficiency, pollutants production under emission limit). It requires convenient interconnection of combustion chamber proper construction and effective combustion process control. Considering inconstant characteristics of the fuel it is necessary to control the amount of combustion air during woodchips supply into furnace and during the combustion too. In case of supplying the large amount of the combustion air, an energy loss occurs (called flue loss). If the amount of air is less than optimum one, incomplete combustion occurs and flue gas contains a part of combustible components. There is necessarity to divide the supplied air into primary and secondary air too (Skok et al., 2009).

\section{CONTROL OF BIOMASS COMBUSTION PROCESS}

The aim of a biomass combustion process control is to provide an optimum combustion. The expression optimum combustion means a complete combustion with minimum excess of the combustion air. Efficiency of the boiler and the emissions of $\mathrm{CO}$ and NOx are dependent on the exess air ratio, as shown on Fig. 1 . The excess air ratio is usually obtained indirectly by measurement of either oxygen or $\mathrm{CO}_{2}$ concentration instead of direct measurement of combustion air flow rate, which would require costly measurement. The most common way of obtaining the value of excess air ratio is using measurement of oxygen concentration by a so-called lambda probe, which is generally an oxygen analyzer working on the principle of electrochemical cell. The value of excess air ratio $\lambda$ can be then obtained as follows (Hrdlička et al., 2010):

$$
\lambda=\frac{21}{21-\mathrm{O}_{2 \%}}
$$

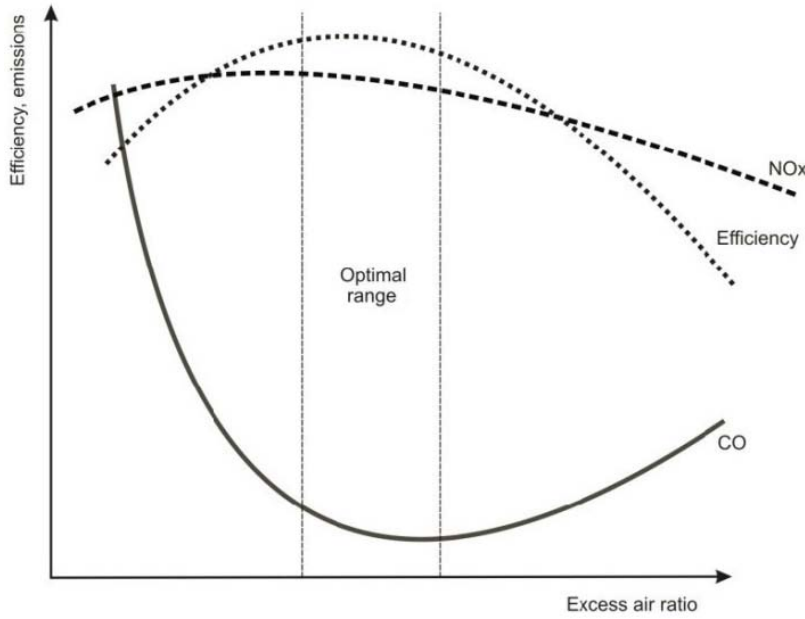

Fig.1. Efficiency, CO and NOx dependency on excess air ratio (Hrdlička et al., 2010)

There are lots of difficulties to increase combustion efficiency by classic approaches to the control of biomass combustion, because especially woodchips and sawdust are characterized in that they have big inhomogeneity. Level of inhomogeneity depends on the type of wood, the moisture content in wood, and it has effect on parameters of the combustion control and the quality of the combustion process (Boržíková, 2010). Nowadays high quality boilers for woodchips and sawdust combustion are already equipped by a sensor of oxygen concentration in the flue gas. But due to very inhomogeneous composition of the woodchips fuel it is very difficult to control of the combustion air amount with aim to achieve the optimal combustion only on the basis of information about oxygen concentration. For that reason, it is necessary to include a sensor or an analyzer into flue gas path to evaluate actual values carbon monoxide concentration (CO). Then one of the control system tasks is to find such lambda value (or optimal interval) from measured dependence $\mathrm{CO}=\mathrm{f}$ (lambda) so that CO would be minimal (Padinger, 2002). But measured values out of optimal interval are unstable and they are very influenced by factors which are specific for concrete combustion process. Therefore it is difficult to approximate measured values only by classical numerical methods, for that reason artificial intelligence techniques have to be used too (Lepold et al., 2009, Pitel' et al., 2010).

\section{APPROXIMATION OF CO/LAMBDA DEPENDENCE}

For many different problems with difficult or impossible finding of formal algorithms to solve them, artificial neural networks can be applied (Saloky et al., 2007). Two approximation tools using neural networks have been tested by authors for approximation of CO/lambda dependence: Neural Network Fitting Tool of Matlab and AForge.Neuro library. 
The Neural Network Fitting Tool (NFTOOL) is a wizard that leads a designer through the process of fitting data using neural networks. There is the tool to import large and complex data sets, quickly create and train networks, and evaluate network performance. It supports a variety of training algorithms, including several gradient descent methods, conjugate gradient methods, the Levenberg-Marquardt algorithm (LM), and the resilient backpropogation algorithm (Rprop). Algorithms can be accessed via a training GUI (Graphical User Interface), which shows a diagram of the network being trained, training algorithm choices, and stopping criteria values as the training progresses. Two-layer feed forward neural network with LM Back-Propagation training algorithm was used for approximation of measured CO/lambda dependence. Approximations with different number of neurons were made. Sufficient results of approximation for using in combustion process control were already reached for minimal number of 2 neurons. Approximated function $\mathrm{CO}=\mathrm{f}(\mathrm{lambda})$ is on Fig. 2, the minimum CO was found for lambda $=1,70$.

AForge.NET framework provides neural networks library named AForge.Neuro, which contains set of classes aimed for creating different type of artificial neural networks and training them to solve certain tasks, like approximation, recognition, prediction, etc. This C\# library implements several popular neural network architectures and their training algorithms, like Back Propagation, Kohonen Self-Organizing Map, Elastic Network, Delta Rule Learning, and Perceptron Learning (Kirillov, 2006). Multilayer feed forward neural network with Error Back-Propagation Learning was used for approximation of measured CO/lambda biomass combustion dependence. The application was created in Microsoft Visual C\# environment by modification of AForge.Neuro example. Different parameters of network and its training were tested. Result of approximation is on Fig. 3, the smallest approximation error was achieved for Learning rate: 0,01, Momentum: 0,4, Sigmoid's alpha value: 0,4 , Neurons in first layer: 2 . The minimum CO was found for lambda $=1,73$.

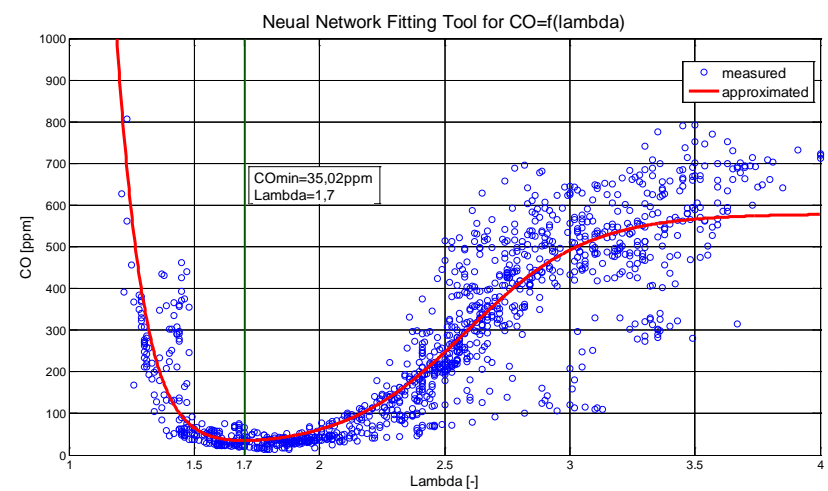

Fig.2. Result of approximation by Neural Network Fitting Tool

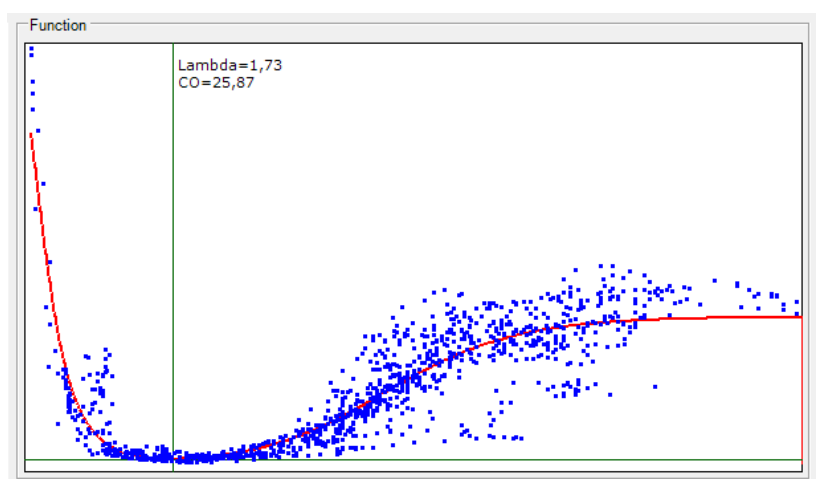

Fig.3. Result of approximation by AForge.Neuro

\section{CONCLUSION}

The comparable results of approximation have been obtained by authors testing of both approximation tools on the real measured data. By using of Network Fitting Tool the results of approximation can be getting for shorter time period with low iteration number and smaller approximation error too. Using of AForge.Neuro allows creating an application in Microsoft Visual C\# environment according to specific requirements for implementation of approximation algorithms into control system supporting C\#.

Further research will be focused on implementation of these tested approximation tools into control algorithms to ensure optimal automatic biomass combustion control without regard to its qualitative parameters.

\section{ACKNOWLEDGEMENTS}

The research work is supported by the Project of the Structural Funds of the EU „Research and development of intelligent control systems for biomass based heat production and supply”, ITMS code: 26220220030.

\section{REFERENCES}

Boržíková, J. (2010). Research and Development of Intelligent Control Systems for Biomass Based Heat Production and Supply, Poceedings of ARTEP 2010, February 24-26, 2010, Stará Lesná, ISBN 978-80-553-0347-5, Šeminský, J. (Ed.), pp. 35-1 - 4, Technical University, Košice

Hrdlička, J.; Šulc, B.; Vrána, S. \& Plaček, V. (2010). Ecological Aspects of Small-Scale Biomass Combustion Control, Proceedings of International Conference on Develepment, Energy, Environment, Economics (DEEE '10), November 30 - December 2, 2010, Puerto De La Cruz, Tenerife, ISBN: 978-960-474-253-0, Mladenov, V. et al (Ed.), pp. 388-393, WSEAS Press

Kirillov, A. (2006). Neural Networks on C\#, Available from: http://www.codeproject.com/KB/recipes/aforge_neuro.aspx Accessed: 2011-03-12

Lepold, M.; Plaček, V.; Vrána, S. \& Šulc, B. (2009). Neural Model of Biomass Fired Boiler Emission Changes Caused by Grate Motion, Poceedings of ARTEP 2009, March 4-6, 2009, Stará Lesná, ISBN 978-80-553-0146-4, Šeminský, J. (Ed.), pp. 52-1 - 7, Technical University, Košice

Padinger, R. (2002). Regelungstechnik für die Haustechnik der Zukunft, Joanneum Research Institut für Energieforschung, Graz

Pitel', J., Boržíková, J. ～\& Mižák, J. (2010). Biomass Combustion Process Control Using Artificial Intelligence Techniques, Proceedings of XXXV. Seminar ASR'2010 "Instruments and Control", April 30, 2010, Ostrava, ISBN 978-80-248-2191-7, Smutný, P. (Ed.), pp. 317-321, VŠBTechnical university, Ostrava

Saloky, T.; Líška, O.; Maxim, V. \& Šeminský, J. (2007). Some problems of neural information processing. TRANSACTIONS of the VŠB - Technical University of Ostrava, Vol. LII, No. 2/2006, pp. 143-148, ISSN 12100471

Skok, P.; Rimár, M. \& Boržíková, J. (2009). On the problems of woodchips combustion, In: Scientific Papers: Operation and diagnostics of machines and production systems operational states, Fabian, S. (Ed.), pp. 63-70, RAMVerlag, ISBN 978-3-9802659-8-0, Lüdenscheid

*** (2011) http://www.aforgenet.com/framework/ - AForge. NET framework, Accessed on: 2011-03-11

*** (2010) http://www.mathworks.com/products/neuralnet/ Neural Network Toolbox: Design and simulate neural network, Accessed on: 2010-06-16 